CHEMISTRY

\section{Crystal harbours molecular shuttle}

A ring-shaped molecule that hops between two sites inside a porous crystal is the first molecular shuttle to operate in a solid-state material.

Molecular shuttles could one day act as switches to store data if they are held in a well-ordered array. A team led by Stephen Loeb and Robert Schurko at the University of Windsor, Canada, built their shuttle inside a metalorganic framework (MOF): a crystalline scaffold made from metal-containing nodes connected by carbon-based struts. These struts bore a circular rotaxane molecule that moved back and forth 283 times per second at room temperature.

The estimated high density of shuttles in the MOF shows the potential for enormous data capacity if such switches can be controlled, the authors say.

Nature Chem. http://doi.org/4f2 (2015)

MICROBIOLOGY

\section{Gut biofilms could spur cancer}

Chemicals secreted by gut bacteria are linked to human colon cancers.

Metabolites called polyamines are made by gut bacteria to help them to form sticky aggregates called biofilms, and are used by human cells to regulate proliferation. Cynthia Sears at Johns Hopkins University in Baltimore, Maryland, Gary Siuzdak at the Scripps Research Institute in La Jolla, California, and their colleagues compared tissue samples from human colon cancers to those from healthy people, both with and without biofilms.

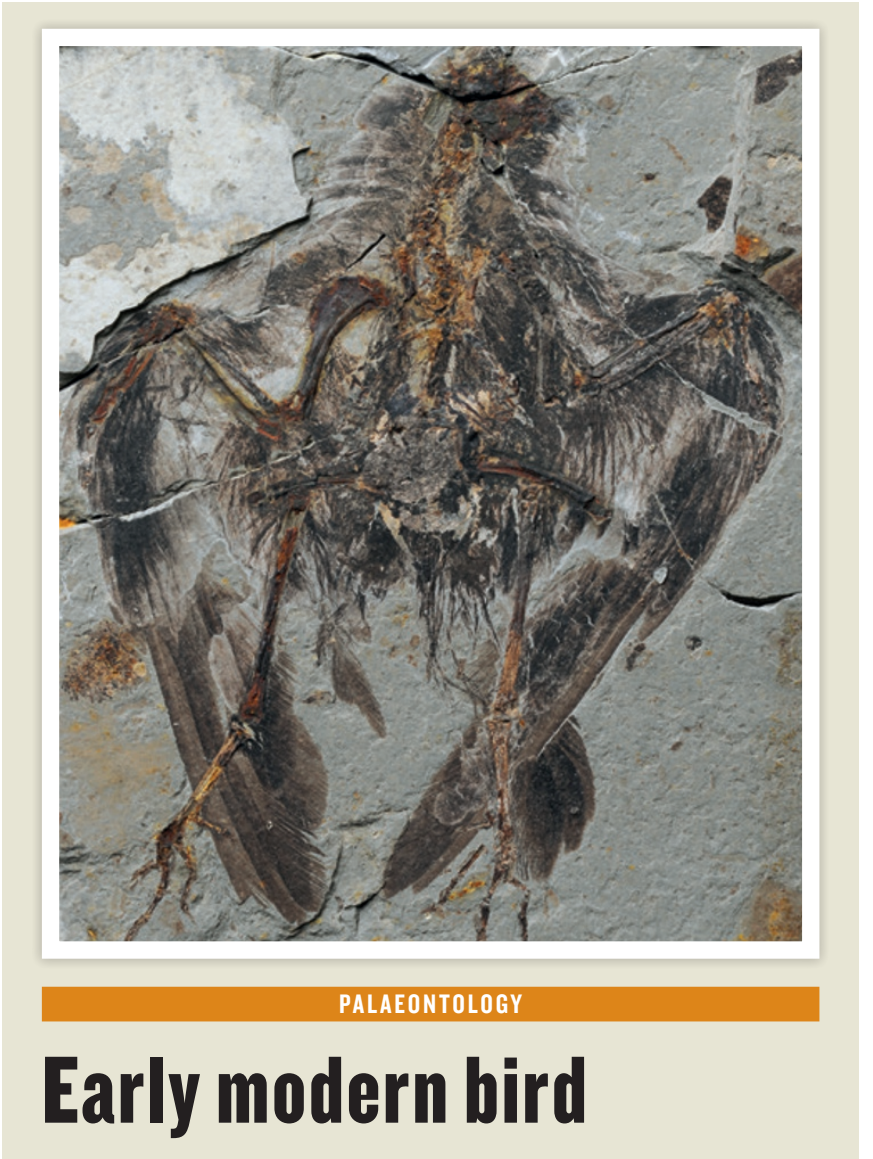

Two newly discovered fossils from China are the oldest relative of modern birds found so far, and had relatively few traits of their dinosaur ancestors.

Min Wang and Zhonghe Zhou at the Institute of Vertebrate Paleontology and Paleoanthropology in Beijing and their colleagues describe two fossils from northeast China dating to 130.7 million years ago. The new species, Archaeornithura meemannae (pictured), boasted elaborate plumage including a fan-shaped tail - and other defining features of modern birds such as a wishbone. This suggests that even these early birds, which are six million years older than previously discovered bird fossils, had already shed key dinosaur traits.

A. meemannae belongs to a family of wading birds, hinting that modern birds originated near water, the team says. Nature Commun. 6, 6987 (2015)
They found that cancer tissue with biofilms had 62 times more of the diacetylspermine than did healthy tissue with biofilms. Yet in samples that were biofilm-free, the cancer tissue contained only around 7 times more polyamine than the polyamine metabolite $N^{1}, N^{12}$. healthy sample. Antibiotic treatment reduced levels of this metabolite, suggesting that it comes from bacteria.

Therapies that target polyamine formation and biofilms could be a way to treat Cell Metab. http://doi.org/4jz (2015) colon cancer, the authors note.
CLIMATE SCIENCE

\section{Growing extremes in California rains}

California's ongoing drought is a result of natural variability, at least for the 2013-14 period. But the state could see larger swings in wet and dry seasons by the end of this century owing to climate change.

Neil Berg and Alex Hall of the University of California, Los Angeles, used 34 climate models to study how precipitation extremes might change in California. They expect that between 2060 and 2100 , the normally wet winter will be extremely dry twice as often as today, and extremely wet three times as often. The fluctuations could raise the risk of drought and flooding.

These changes could push the state's water supply to its limit.

J. Clim. http://doi.org/4fz (2015)

\section{EVOLUTION}

\section{Bird beak to dinosaur snout}

Chicken embryos with dinosaur-like faces provide clues as to how bird beaks evolved from dinosaur snouts.

Early in bird evolution, the twin bones that form the snout in dinosaurs and reptiles - the premaxillae - grew longer and joined together, eventually forming the beak. Bhart-Anjan Bhullar, now at the University of Chicago in Illinois, Arhat Abzhanov at Harvard University in Cambridge, Massachusetts, and their colleagues analysed the development of beaks in embryonic chickens and emus, and snout development in reptiles such as alligators.

They found that two proteins involved in facial development, FGF and Wnt, might have a role in beak evolution. When 
they inhibited these genes in developing chicken eggs making the expression pattern more like that of reptiles and other vertebrates - the premaxillae were separate and much shorter in some chicken embryos than in others. (None was allowed to hatch.)

$\mathrm{X}$-ray scans of the embryonic skulls showed that they more closely resembled the bones of early birds and dinosaurs than those of modern chickens. Evolution http://dx.doi.org/ 10.1111/evo.12684 (2015)

\section{ENTOMOLOGY}

\section{Ants dig differently depending on dirt}

Fire ants adjust their digging behaviour when building underground nests, depending on the size and dampness of the material they are working with.

Daniel Goldman and his colleagues at the Georgia Institute of Technology in Atlanta studied fire ants (Solenopsis invicta; pictured) as they constructed tunnel networks in silica particles designed to mimic soil of varying moisture levels and particle size. Using X-ray imaging, the team found that up to a point, ants dug deeper tunnels through clay-like and fine-grained particles as the moisture content increased, using the growing stickiness of the particles. When digging, the ants either carried individual grains away if they were large, or gathered and compressed smaller particles into a pellet.

The authors say that this adaptability could help to explain how this species has successfully colonized large

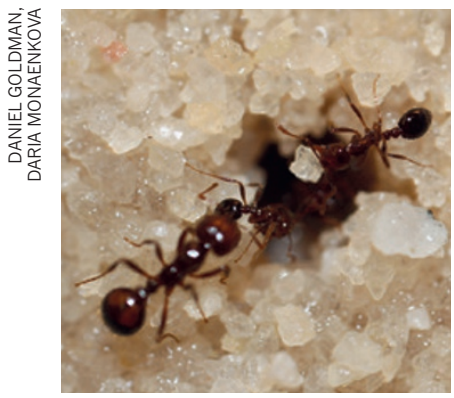

parts of North America. J. Exp. Biol. 218, 1295-1305 (2015)

\section{ASTROPHYSICS}

\section{Farthest galaxy measured}

Astronomers have observed a distant galaxy as it looked just 650 million years after the Big Bang, making it the farthest galaxy to have its distance reliably measured.

Pascal Oesch at Yale University in New Haven, Connecticut, and his colleagues used a telescope at the W. M. Keck Observatory in Hawaii to study the galaxy EGS-zs8-1. To gauge its age, they measured how much its light had been stretched, or redshifted, as the light travelled across the expanding Universe. They found that the object is surprisingly bright and massive for such a young galaxy - a sign of rapid star formation.

Their analysis adds weight to a theory that the peculiar colours of early galaxies, compared to later objects, may be the result of interaction between these rapidly forming stars and the gas around them. Astrophys. J. Lett. 804, L30 (2015)

\section{INFECTIOUS DISEASE}

\section{Silenced gene keeps malaria out}

Researchers have uncovered a possible target for anti-malarial therapies by suppressing gene expression in blood stem cells.

Malaria-causing parasites attack mature red blood cells, which lack DNA, making it hard to test which genes make the cells vulnerable to malaria infection. Manoj Duraisingh at the Harvard T. H. Chan School of Public Health in Boston, Massachusetts, and his colleagues have sidestepped this problem by studying the stem cells that develop into red blood cells and contain DNA.

They used RNA molecules to knock down gene activity in the stem cells, induced them to develop into red blood cells and then exposed them to

\section{SOCIAL SELECTION Rominaricies}

\section{Mystery of telescope signals solved}

A report on the surprising origins of rogue signals picked up by a radio telescope has been simmering on social media. After more than four years, researchers using the Parkes radio telescope in New South Wales, Australia, have identified the source of the mysterious signals: a microwave oven in the facility's break room. The news quickly spread on Twitter. "And the result of the story: don't use microwaves next to radio telescopes!" tweeted Karina Voggel, an astronomy $\mathrm{PhD}$ student at the European Southern Observatory in Garching, Germany. "A nice reminder that not all radio transients are microwave ovens - even if some are," tweeted Chris Lintott, an astrophysicist at the University of Oxford, UK. http://arXiv.org/abs/1504.02165v1 (2015)

\section{Based on data from altmetric.com. Altmetric is supported by Macmillan Science and Education, which owns Nature Publishing Group.}

DNATURE.COM

For more on popular papers: go.nature.com/07mhip

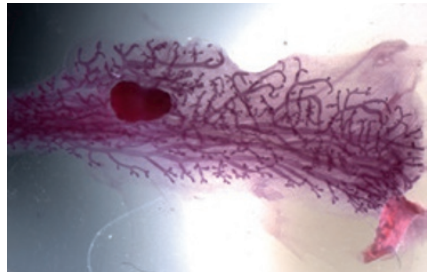

Plasmodium falciparum - the most deadly malaria pathogen.

They found that the parasite binds to a cell-surface protein called CD55 and could not infect cells that did not produce it. Red blood cells can function normally without CD55, suggesting that the protein could be a therapeutic target.

Science 348, 711-714 (2015)

\section{EPIGENETICS \\ Mammary cells have a memory}

Specific DNA changes make the mammary glands in pregnant mice gear up for milk production faster if the animals have been pregnant before.

Many women report that breast-feeding becomes easier with each pregnancy. To find out why, Gregory Hannon at Cold Spring Harbor Laboratory in New York and his colleagues gave pregnancy

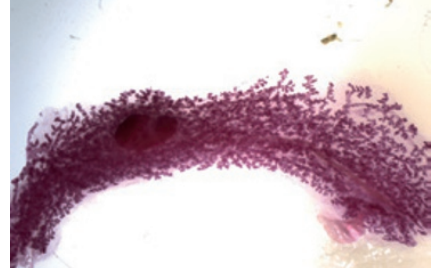

hormones to female mice and monitored changes in their mammary glands over time.

In mice that had been pregnant once before, the milkproducing ducts expanded in number more quickly (pictured, right) and generated milk proteins sooner than the ducts of mice that were firsttime mothers (pictured, left). Genetic analysis of mammarygland cells after the animals had stopped lactating showed that a previous pregnancy resulted in a long-term loss of methyl groups from DNA in genes that are activated during lactation.

This epigenetic 'memory' primes these genes for fast reactivation in a subsequent pregnancy, the authors say. Cell Rep. http://doi.org/4j2 (2015)

\section{DNATURE.COM}

For the latest research published by Naturevisit:

www.nature.com/latestresearch 